\title{
Genetics of Parkinson's disease in Brazil: a systematic review of monogenic forms
}

\author{
Genética da doença de Parkinson no Brasil: revisão sistemática de formas monogênicas \\ Bruno L. SANTOS-LOBATO1,2, Artur SCHUMACHER-SCHUH ${ }^{3,4}$, Ignacio F. MATA ${ }^{5}$, Grace H. LETRO ${ }^{6}$, Pedro \\ BRAGA-NETO7, Pedro R. P. BRANDÃO², Clécio O. GODEIRO-JUNIOR ${ }^{9}$, Marcus V. DELLA COLETTA ${ }^{10}$, Sarah \\ T. CAMARGOS ${ }^{11}$, Vanderci BORGES ${ }^{12}$, Carlos R. M. RIEDER ${ }^{13}$, Vitor TUMAS ${ }^{14}$ on behalf of the Brazilian \\ Consortium of Parkinson's Disease
}

\begin{abstract}
Background: Increasing numbers of mutations causing monogenic forms of Parkinson's disease (PD) have been described, mostly among patients in Europe and North America. Since genetic architecture varies between different populations, studying the specific genetic profile of Brazilian patients is essential for improving genetic counseling and for selecting patients for clinical trials. Objective: We conducted a systematic review to identify genetic studies on Brazilian patients and to set a background for future studies on monogenic forms of PD in Brazil. Methods: We searched MEDLINE, EMBASE and Web of Science from inception to December 2019 using terms for "Parkinson's disease", "genetics" and "Brazil". Two independent reviewers extracted the data. For the genes LRRK2 and PRKN, the estimated prevalence was calculated for each study, and a meta-analysis was performed. Results: A total of 32 studies were included, comprising 94 Brazilian patients with PD with a causative mutation, identified from among 2,872 screened patients (3.2\%). PRKN mutations were causative of PD in 48 patients out of 576 (8.3\%). LRRK2 mutations were identified in 40 out of 1,556 patients (2.5\%), and p.G2019S was the most common mutation (2.2\%). Conclusions: PRKN is the most common autosomal recessive cause of PD, and LRRK2 is the most common autosomal dominant form. We observed that there was a lack of robust epidemiological studies on PD genetics in Brazil and, especially, that the diversity of Brazil's population had not been considered.
\end{abstract}

Keywords: Genetics; Parkinson's disease; LRRK2; PRKN.

\footnotetext{
${ }^{1}$ Universidade Federal do Pará, Laboratório de Neuropatologia Experimental, Belém PA, Brazil.

${ }^{2}$ Hospital Ophir Loyola, Serviço de Neurologia, Belém PA, Brazil.

${ }^{3}$ Hospital de Clínicas de Porto Alegre, Serviço de Neurologia, Porto Alegre RS, Brazil.

4 Universidade Federal do Rio Grande do Sul, Departamento de Farmacologia, Porto Alegre RS, Brazil.

${ }^{5}$ Lerner Research Institute, Genomic Medicine, Cleveland Clinic, Cleveland, OH USA.

${ }^{6}$ Pontifícia Universidade Católica de Campinas, Centro de Ciências da Vida, Campinas SP, Brazil.

`Universidade Federal do Ceará, Departamento de Medicina Clínica, Serviço de Neurologia e Neurocirurgia, Fortaleza CE, Brazil.

¿Universidade de Brasília, Laboratório de Neurociências e Comportamento, Brasília DF, Brazil.

'Universidade Federal do Rio Grande do Norte, Departamento de Medicina Integrada, Natal RN, Brazil.

${ }^{10}$ Universidade do Estado do Amazonas, Fundação Hospital Adriano Jorge, Manaus AM, Brazil.

${ }^{11}$ Universidade Federal de Minas Gerais, Departamento de Medicina Interna, Belo Horizonte MG, Brazil.

${ }^{12}$ Universidade Federal de São Paulo, Departamento de Neurologia e Neurocirurgia, Setor de Transtornos de Movimento, São Paulo SP, Brazil.

${ }^{13}$ Universidade Federal de Ciências da Saúde de Porto Alegre, Departamento de Neurologia, Porto Alegre RS, Brazil.

${ }^{14}$ Universidade de São Paulo, Faculdade de Medicina de Ribeirão Preto, Departamento de Neurociências e Ciências do Comportamento, Ribeirão Preto SP, Brazil.

Bruno L. Santos-Lobato (iD https://orcid.org/0000-0001-9321-5710; Artur Schumacher-Schuh (iD https://orcid.org/0000-0002-8722-0908; Ignacio F. Mata (iD https://orcid.org/0000-0003-1198-0633; Grace H. Letro (D) https://orcid.org/0000-0002-3815-9514; Pedro Braga-Neto (D) https://orcid.org/0000-0001-91869243; Pedro R. P. Brandão (iD https://orcid.org/0000-0002-1191-2078; Clécio O. Godeiro-Junior (ID) https://orcid.org/0000-0002-4312-1633; Marcus V. Della Coletta (iD https://orcid.org/0000-0002-3368-8492; Sarah T. Camargos (D) https://orcid.org/0000-0001-9829-6783;Vanderci Borges (DD https://orcid.org/00000002-8723-2757; Carlos R. M. Rieder (D) https://orcid.org/0000-0003-2950-7211;Vitor Tumas (D) https://orcid.org/0000-0003-2402-2709

Correspondence: Vitor Tumas; Email:tumasv@rnp.fmrp.usp.br.

Conflict of interest declarations: Dr. Santos-Lobato has no conflicts of interest; Dr. Schumacher-Schuh has no conflicts of interest; Dr. Mata has no conflicts of interest; Dr. Letro has no conflicts of interest; Dr. Braga-Neto received fees from Actelion Janssen and Teva for presentation of lectures, and a grant from the Brazilian National Council for Scientific and Technological Development; Dr. Brandão has no conflicts of interest; Dr. Godeiro-Junior received educational support from Roche; Dr. Della Coletta has no conflicts of interest; Dr. Camargos received fees from Roche and Teva for presentation of lectures, and received support from Roche and Centogene for congress attendance; Dr. Borges received honoraria from UCB Pharma; Dr. Rieder served on Advisory Boards of Teva Brasil, UCB Biopharma, Medtronic and Rocha, received support from Roche for congress attendance, and received a grant from the Brazilian National Council for Scientific and Technological Development; Dr. Tumas received honoraria from Teva Brasil, UCB Biopharma and Ipsen, and travel support from Roche for medical conferences.

Authors' contributions: Bruno L. Santos-Lobato, Artur Schumacher-Schuh, Ignacio F. Mata, Carlos R. M. Rieder and Vitor Tumas contributed to conception and organization of the manuscript. All authors wrote and critically evaluated the first draft of the manuscript. All authors approved the final version of the manuscript for submission.
}

Received on August 25, 2020; Received in final form on September 15, 2020; Accepted on September 17, 2020. 


\section{RESUMO}

Introdução: Um número crescente de mutações causando formas monogênicas de doença de Parkinson (DP) tem sido descrito, principalmente entre pacientes da Europa e da América do Norte. Como a arquitetura genética varia entre diferentes populações, entender os perfis genéticos específicos de pacientes brasileiros é essencial para um melhor aconselhamento genético e para a seleção de participantes para ensaios clínicos. Objetivo: Revisão sistemática para identificar estudos genéticos brasileiros na área e definir o cenário para estudos futuros das formas monogênicas de DP no Brasil. Métodos: Nós pesquisamos as bases de dados MEDLINE, EMBASE e Web of Science desde a criação até dezembro de 2019, usando termos para "Parkinson's disease", "genetics" e "Brazil". A extração de dados foi feita por dois revisores independentes. Para os genes $L R R K 2$ e PRKN, calculamos a prevalência estimada para cada estudo e realizamos uma meta-análise. Resultados: Um total de 32 estudos foram incluídos e 94 pacientes brasileiros com DP com mutações causativas foram identificados em 2872 pacientes avaliados (3.2\%). As mutações no PRKN causaram DP em 48 de 576 pacientes (8.3\%). As mutações no LRRK2 foram identificadas em 40 de 1566 pacientes (2.5\%), sendo a mutação mais comum a p.G2019S (2.2\%). Conclusões: As mutações na PRKN são a causa mais comum de DP autossômica recessiva, e as mutações no LRRK2 a causa mais comum de DP autossômica dominante. Nós observamos uma falta de estudos epidemiológicos robustos em genética de DP, especialmente por não levar em conta a diversidade de nossa população.

Palavras-chave: Genética; doença de Parkinson; LRRK2; PRKN.

\section{INTRODUCTION}

Over recent decades, mutations in several genes have been linked to inherited forms of Parkinson's disease (PD). After alpha-synuclein gene ( $S N C A)$ mutations were reported to be a monogenic cause of parkinsonism ${ }^{1}$, several other genetic forms of the disease were described, including those with autosomal dominant inheritance, such as with the genes LRRK2, SNCA, VPS35, ATXN2 and GCH1, and others with recessive inheritance, such as with the genes PRKN, PINKI and $D J 1$. Some other autosomal recessive mutations cause atypical parkinsonism, such as with the genes ATP13A2, PLA2G6, SYNJ1, SPG11, FBXO7 and VPS13C. Mutations in the $\mathrm{X}$-linked $R A B 39 B$ gene have also been described as causing parkinsonism ${ }^{1}$.

Some of these mutations, such as the LRRK2 point mutation c.6055G>A (p.G2019S), are highly population-specific. While virtually absent among Asians and with low prevalence in Europeans (1-4\% of sporadic PD and up to $14 \%$ of familial PD cases), LRRK2 mutations can be found in up to $28 \%$ of Ashkenazi Jewish and 38\% of North-African Arab patients².

Brazil is the fifth most populous country in the world, with more than 210 million inhabitants; approximately $14 \%$ of the population is aged 60 years or over, and it has been estimated that this proportion will rise to $32 \%$ by $2060^{3}$. The Brazilian population has significant genetic variability due to the interactions between Amerindian populations, Portuguese settlers and enslaved African people starting at the beginning of the 16th century; and subsequent interactions with individuals who migrated from other nations (like Italians, Japanese and Germans) in the $19^{\text {th }}$ century ${ }^{4}$. Because of this genetic diversity, the frequency of different monogenic causes of PD can differ from those observed in other regions of the world. This can also vary significantly according to the different regions of the country and between socioeconomic classes.
To identify these gaps in knowledge and lay the foundation for future projects in this country, we conducted a systematic review of previously published studies on monogenic forms of PD among Brazilian patients. Our aims were to provide a broad view of studies describing genetic forms of $\mathrm{PD}$ in Brazilian patients, and to perform a meta-analysis to estimate the prevalences of the better-explored monogenic PD mutations in Brazil.

\section{METHODS}

\section{Search strategy}

We conducted a systematic search of the literature in MEDLINE, EMBASE and Web of Science (from inception to December 2019) using the following algorithms: MEDLINE - "Parkinson's disease" AND Brazil AND genetics; EMBASE ('parkinson disease'/exp OR 'parkinson disease') AND ('brazil'/exp OR brazil) AND ('genetics'/exp OR genetics); Web of Science - ALL=(“Parkinson's disease" AND Brazil AND genetics). Reference lists of studies that were included were checked to identify any additional studies that might have been missed in the primary search (cross-reference search).

\section{Study selection}

We aimed to select any original research study describing Brazilian patients with monogenic forms of PD. Two rounds of selection were performed. In the first round, titles and abstracts were screened and exclusions were made based on these exclusion criteria: (1) studies without a description of the genetic forms of PD in Brazilian patients; (2) studies not conducted on human subjects; and (3) duplicated articles. In the second round, full texts were evaluated and exclusions were made based on other exclusion criteria: (1) review studies; (2) studies on cases of patients with genetic forms of PD that had already described, without making any new 
contributions; (3) studies assessing different conditions (such as atypical parkinsonism or dementia with Lewy bodies); (4) conference abstracts; and (5) full text not found. Two reviewers performed each selection round independently and disagreements were resolved by reaching a consensus. The potential pathogenicity of the variants reported was assessed based on the methodology of the International Parkinson Disease and Movement Disorder Society Genetic Mutation Database (https://www.mdsgene.org/methods) ${ }^{5}$ and on the ClinVar database of the National Institute of Health, USA (https://www.ncbi.nlm.nih.gov/clinvar/)'.

\section{Data extraction}

Two independent reviewers extracted the data using a spreadsheet, in which the following items were reported: (1) first author's name; (2) year of publication; (3) Brazilian region involved in the study; (4) study design; (5) studies with family history as an inclusion criteria for patients (defined as any positive family history); (6) studies with early-onset PD (EOPD) as an inclusion criteria (cutoff age at onset ranging from 40 to 55 years between studies); (7) sample size, sex and age of the study population (patients and controls); (7) genes analyzed; (8) number of mutations described; and (9) zygosity of mutations.

\section{Statistical analysis}

The number and prevalence of mutations in genes described in Brazilian patients with PD were calculated. We considered that PRKN and LRRK2 were the genes most explored in studies and, hence, we proceeded with further analyses on mutations in these genes. For these analyses, we excluded family case studies and case reports/series due to the high possibility of selection bias. A random-effects model was used to estimate the weighted pooled prevalence of mutations in PRKN and LRRK2. To assess the heterogeneity between the studies, the $\mathrm{I}^{2}$ test was used, and $\mathrm{I}^{2}$ above $75 \%$ was taken to indicate high heterogeneity. The analyses were performed using MetaXL 5.3 (Epigear International, Sunrise Beach, Australia), which is an add-in for Microsoft Excel.

\section{RESULTS}

After pooling the publications from database searches, a total of 343 articles were found. After the first round, 44 articles were selected for full-text examined. From these, a total of 32 articles were finally included and reviewed (Table 1). Twenty-three studies were mutation screenings, seven were family studies, and two were case reports. Twelve studies were international collaborations that included Brazilian groups. Among the studies exclusively conducted in Brazil, only seven involved collaborations between groups in different regions of this country. According to the participation of Brazilian regions in these studies, patients in the Southeastern region were included in 25 studies, in the Southern region in nine studies, in the Central-western region in seven studies, in the Northern region in three studies and in the Northeastern region in three studies (Figure 1). Fifteen studies strictly only included patients with a family history of PD, and 16 studies strictly only included patients with EOPD. Among all these studies, 94 mutations were reported among approximately 2,872 Brazilian PD patients (3.2\%). The mean age at evaluation and age at onset were 55.9 and 44.6 years, respectively. Nine genes were analyzed, and mutations in five genes were described (Table 2).

Fifteen studies assessed the prevalence of LRRK2 mutations among 1,556 patients, finding a total of 40 patients (2.5\%) carrying LRRK2 mutations. Four of these studies only included patients with familial PD (total of 233 patients; $14.9 \%$ of all patients screened for $L R R K 2$ mutations), and five studies only included patients with EOPD (total of 410 patients; $26.3 \%$ of all patients screened for LRRK2 mutations). There were no homozygous or compound heterozygous mutations. The mean age at onset was 49.9 years (95\% CI, 45.1-54.6) and a positive family history was found among $45.4 \%$ of the patients with PD carrying $L R R K 2$ mutations. The most common mutation in the LRRK2 gene was p.G2019S ( $\mathrm{n}=35$ ), followed by p.Y2189C ( $\mathrm{n}=2)$ and p.C2139S, p.R1441C and p.Q923H (each of these last mutations was detected in one patient) (Figure 2). However, nine studies explored only the p.G2019S mutation, and three studies sequenced the whole LRRK2 gene, thus probably overestimating the frequency of this mutation in Brazilian patients with PD. Only p.G2019S and p.R1441C were classified as definitely pathogenic mutations, and the other mutations (p.Y2189C, p.C2139S and p.Q923H) were classified as variants of uncertain significance. In accordance with the methodology described above, we selected eight studies for meta-analysis $(\mathrm{n}=1,257)$. The random-effect model showed that the weighted pooled prevalence of LRRK2 mutations in Brazilian patients with PD was 3.5\% (95\% CI, 2.2\%-5.0\%), with moderate heterogeneity between the studies analyzed $\left(\mathrm{I}^{2}=37.4 \% ; \mathrm{p}=0.13\right)$ (Figure 3A). Comparing only the studies that included strictly EOPD or familial PD patients, the weighted pooled prevalence of LRRK2 mutations was 5.4\% (95\% CI, 2.7\%-9.0\%) in three studies that included strictly EOPD patients $(\mathrm{n}=208)$ (Figure $3 \mathrm{~B})$, and 5\% $(95 \% \mathrm{CI}, 1.9 \%$ 9.2\%) in two studies that included strictly familial PD patients $(\mathrm{n}=224)$ (Figure 3C).

Twelve studies assessed the prevalence of PRKN mutations among a total of 576 patients, finding a total of 48 patients (8.3\%) carrying PRKN mutations. Five of these studies only included patients with familial PD (total of 25 patients; $4.3 \%$ of all patients screened for PRKN mutations), and eight studies only included patients with EOPD (total of 559 patients; $97 \%$ of all patients screened for PRKN mutations). Among these mutations, $43.7 \%$ were homozygous and 


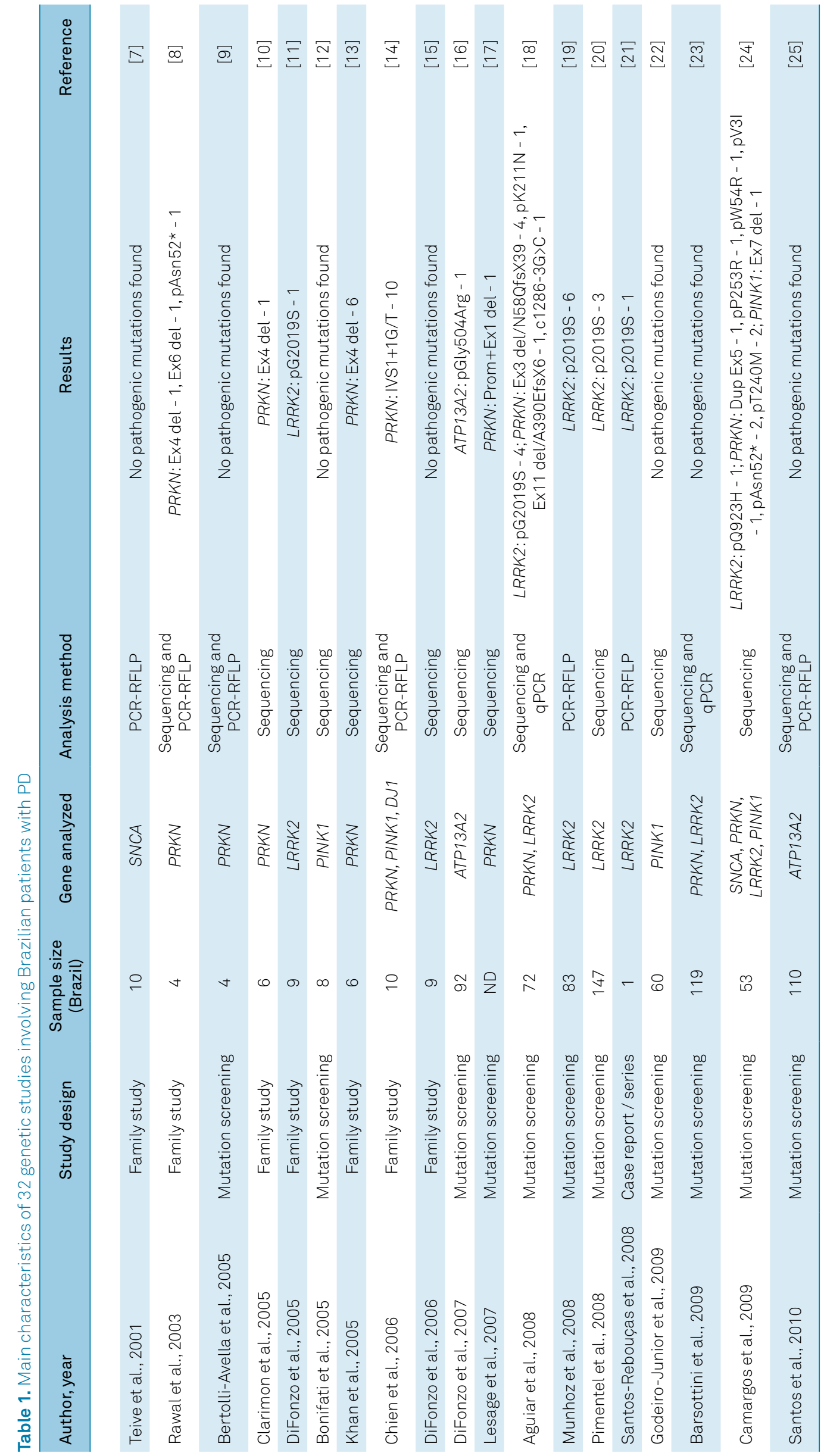




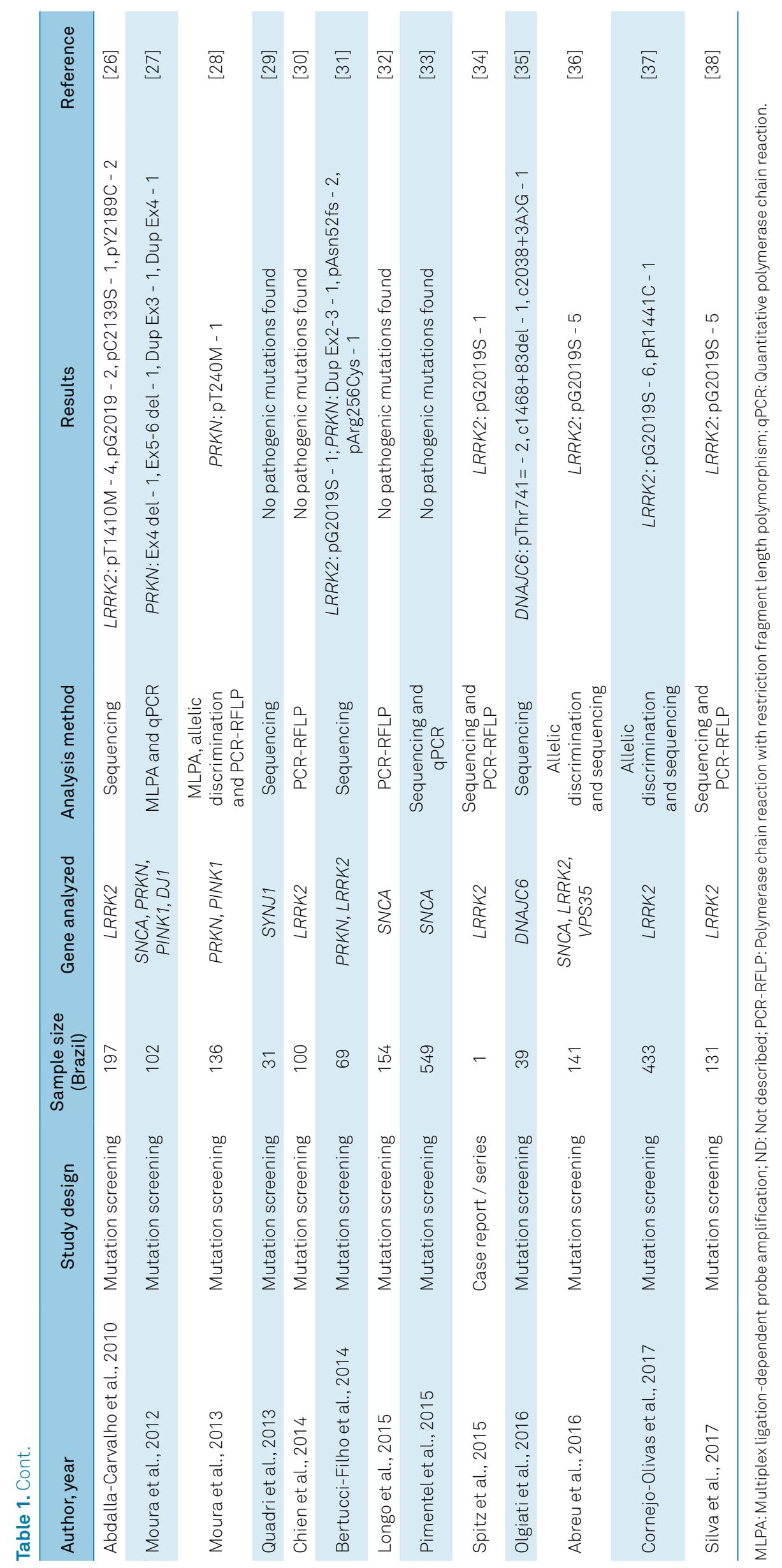


State Number of studies

1 study

São Paulo

Rio de Janeiro

14

10

Goiás

Paraná

Rio Grande do Sul

Amazonas

Ceará

Paraíba

Minas Gerais

Federal District

6

5

4

4

2

1

1

1

B

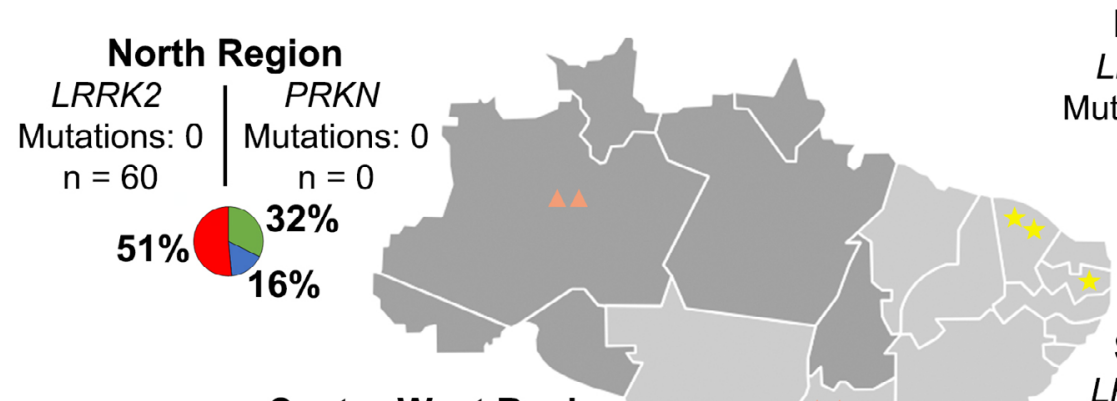

Northeast Region

LRRK2 PRKN

Mutations: 0 Mutations: 17

\begin{tabular}{l|l}
$n=0$ & $n=17$
\end{tabular}

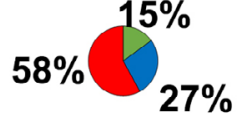

Southeast Region

Center-West Region

LRRK2

PRKN

Mutations: 1 Mutations: 0

$$
\mathrm{n}=76 \quad \mathrm{n}=25
$$

Mutation screening study

Family study

$12 \%$

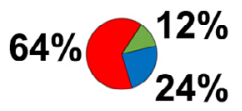

LRRK2

PRKN

Case report / series

European ancestry

African ancestry

Amerindian ancestry

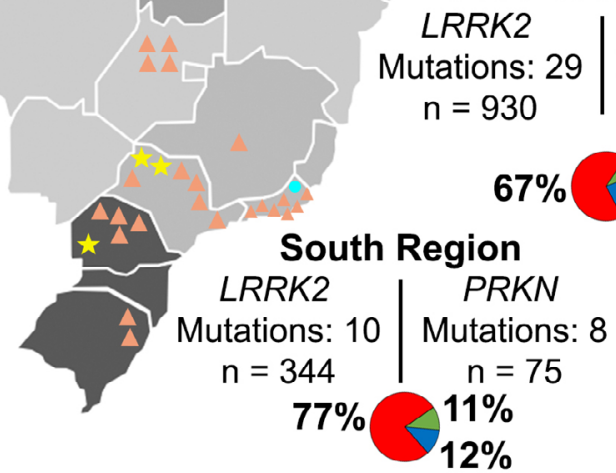

Figure 1. Distribution of monogenic forms of PD described in Brazil. A: Distribution of studies on monogenic forms of PD in Brazil according to states. B: Distribution of $L R R K 2$ and PRKN mutations in Brazil according to regions (depicted in different shades of gray). Studies are represented by symbols, according to the type of study design. Ancestry proportions of each region are represented in pie charts, based on Moura et al., $2015^{4}$.

Table 2. List of genes investigated and mutations identified in Brazilian patients with PD.

Genes investigated in Brazilian patients with PD

ATP13A2

DJ1

DNAJC6

LRRK2

PINK1

PRKN

SNCA

SYNJ1

VPS35
Genes with mutation identified in Brazilian patients with PD

ATP13A2

DNAJC6

LRRK2

PINK1

PRKN 

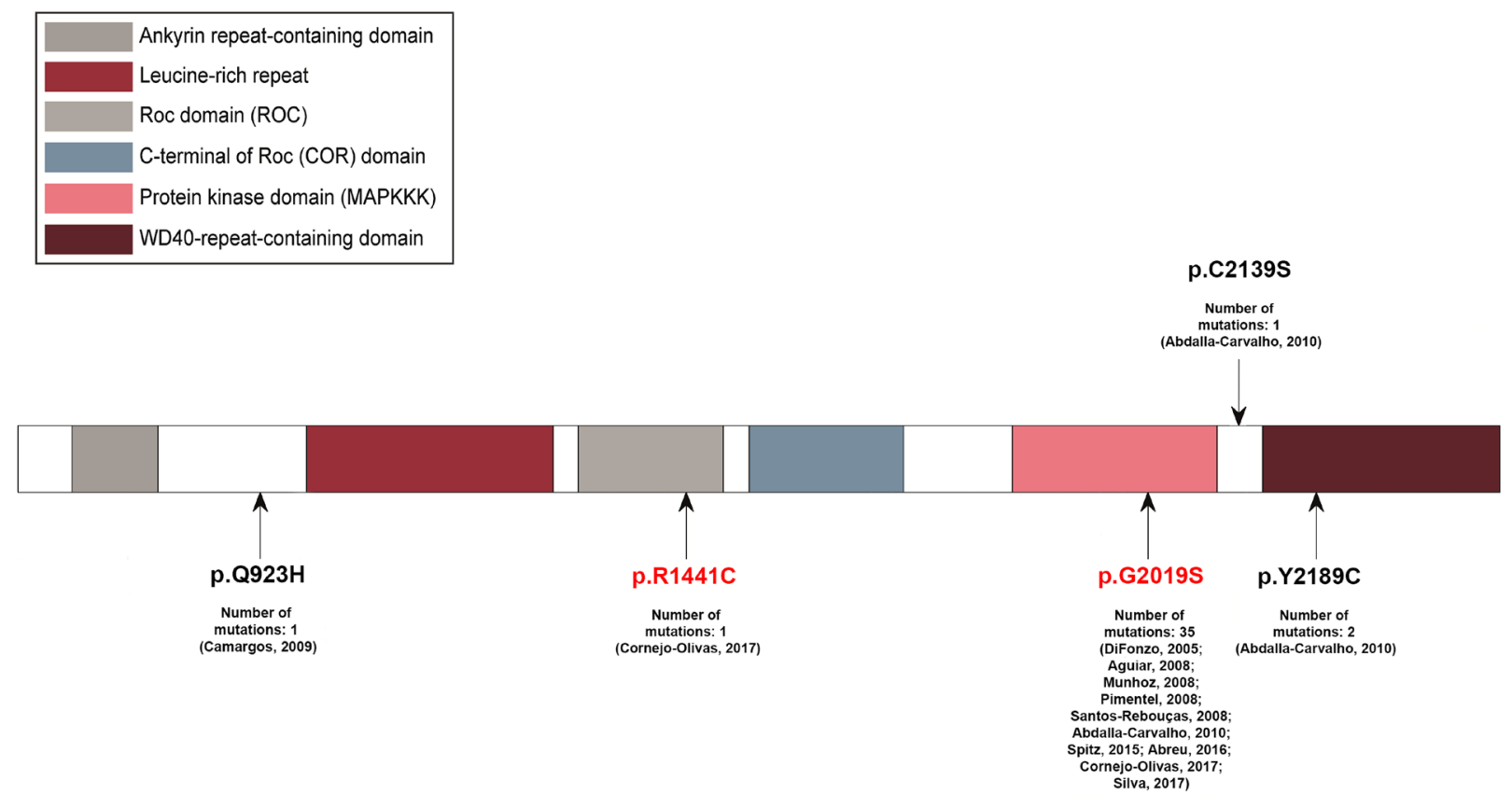

Figure 2. Schematic representation of LRRK2 protein domains, and locations of mutations described in Brazilian patients with PD, adapted from the website of the Movement Disorder Society Genetic Mutation Database ${ }^{5}$. Arrows indicate the locations of point mutations. Definitely pathogenic mutations are indicated in red letters and variants of uncertain significance in black letters.

$12.5 \%$ were compound heterozygous. The mean age at onset was 31.8 years $(95 \%$ CI, 28.5-35.1) and there was a positive family history among $66.6 \%$ of the patients carrying PRKN mutations, including copy number variations, single nucleotide variants and frameshift mutations (Figure 4). The most common mutations in $P R K N$ were IVS1+1G/T $(\mathrm{n}=10)$ and a deletion in exon $4(n=9)$. Two mutations were classified as probably pathogenic (p.R256C and c.1286-3G>C), and four as variants of uncertain significance (IVS1+1G/T, p.P253R, p.V3I and p.W54R) due their rarity; all other mutations were classified as definitely pathogenic. We selected four studies for meta-analysis; these studies included strictly EOPD patients, and none included only familial PD patients $(n=296)$. The random-effect model showed that the weighted pooled prevalence of PRKN mutations in Brazilian EOPD patients was 9.3\% (95\% CI, 4.4\%-15.6\%), with high heterogeneity between the studies analyzed $\left(\mathrm{I}^{2}=62.9 \% ; \mathrm{p}=0.04\right)$ (Figure 5$)$.

There were descriptions of mutations in other three genes: four patients with DNAJC6 mutations (two patients homozygous for p.T741=, one with compound heterozygosity for c.1468+83del and one with compound heterozygosity for c. $2038+3 \mathrm{~A}>\mathrm{G}$ ), one patient with PINK1 mutation (homozygous deletion in exon 7) and one patient with an ATP13A2 homozygous mutation (p.G504R). The PINK1 deletion in exon 7 and ATP13A2 p.G504R was classified as probably pathogenic, DNAJC6 p.T741= as possibly pathogenic and DNAJC6 c.1468+83del and c.2038+3A $>\mathrm{G}$ as variants of uncertain significance.

\section{DISCUSSION}

We found in this systematic review that there is a significant number of studies on monogenic forms of PD in Brazilian patients, in which around 3,000 patients were evaluated. Most of these studies were mutation screenings. Mutations in nine genes related to PD were investigated: SNCA, PRKN, LRRK2, PINK1, DJ1, VPS35, ATP13A2, DNAJC6 and SYNJ1; mutations were found in five of them: PRKN, LRRK2, PINK1, ATP13A2 and DNAJC6. The two genes most studied in Brazilian patients were PRKN and LRRK2. This finding was expected, as these monogenic forms of $\mathrm{PD}$ are the most common forms worldwide ${ }^{1}$.

The LRRK2 p.G2019S point mutation is the most common associated variant that causes monogenic $\mathrm{PD}^{2}$, and it also seems to be the most important cause of LRRK2 PD in the Brazilian population to date. We estimated that the weighted pooled prevalence of LRRK2 mutations was $3.5 \%$ among all the Brazilian patients evaluated here, and $5 \%$ among familial PD cases. However, considering the low level of inclusion of familial PD patients, and that most studies only screened for the p.G2019S mutation, these prevalences may be imprecise. These Brazilian findings are similar to worldwide data, in 


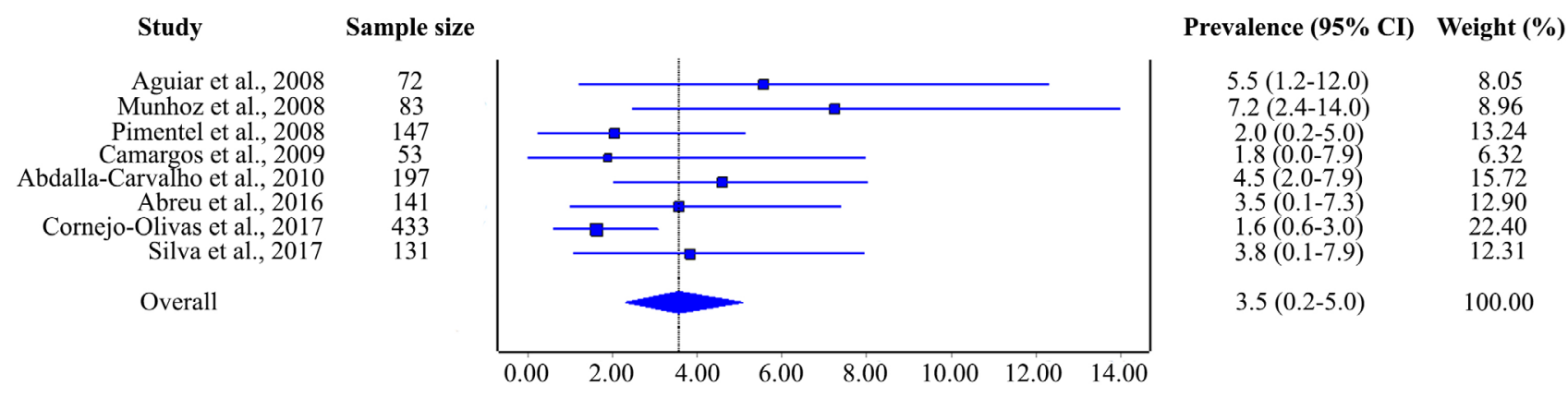

B
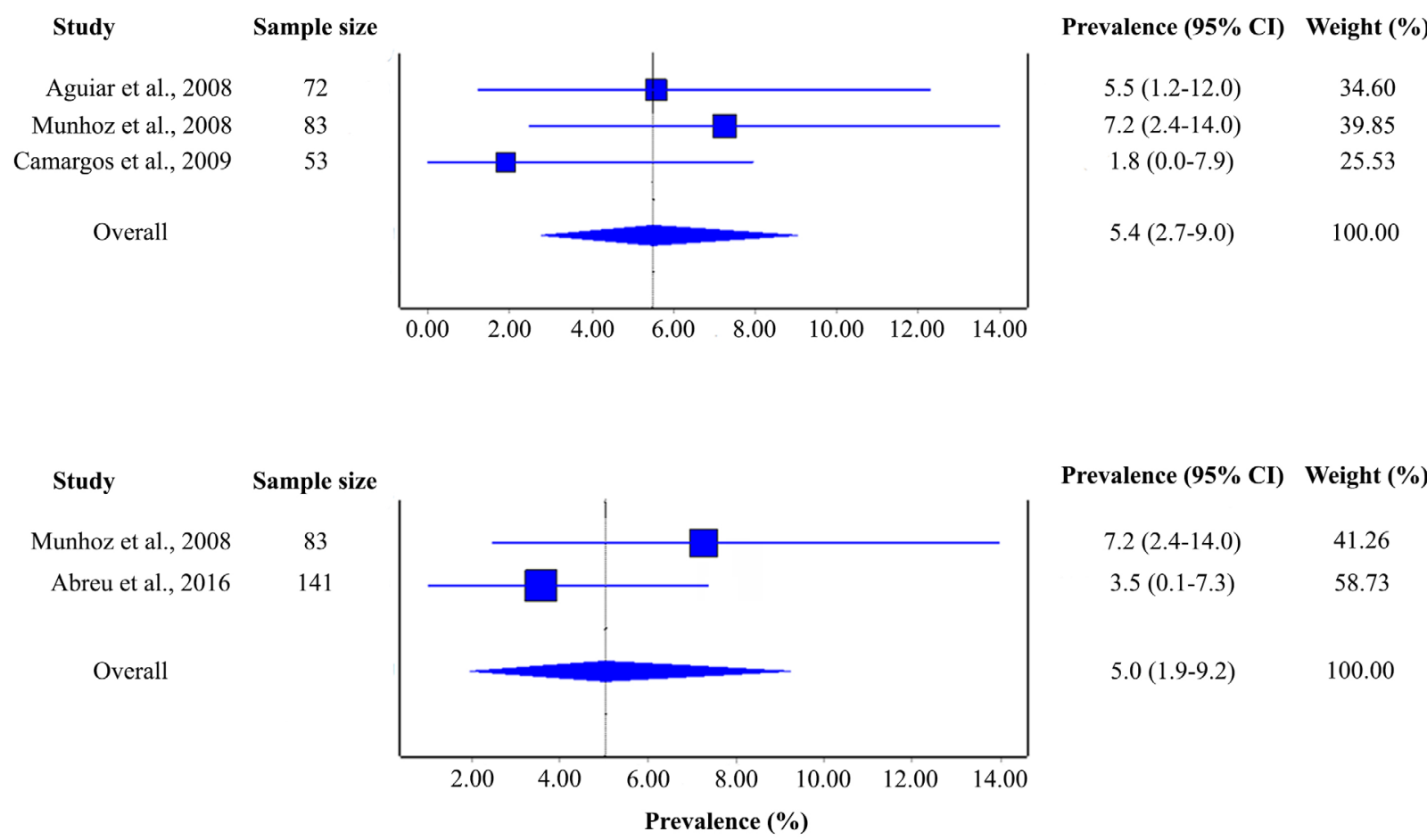

Figure 3. Forest plot of prevalence of LRRK2 mutation-positive Brazilian patients with PD and 95\% confidence intervals for each study included in the meta-analysis. A: Analysis with all studies. B: Analysis with studies that strictly included early-onset PD cases. C: Analysis with studies that strictly included familial PD cases. Right-hand column shows per-study prevalence of mutation-positive cases for LRRK2 (\%), 95\% confidence intervals and the weighting (\%) of each study. The overall weighted prevalence in the random-effects model is denoted by a blue diamond and dotted line. Blue squares are in proportion to the weighting of each study, and blue bars show confidence intervals.

which LRRK2 p.G2019S point mutations are present in 1-5\% of patients with sporadic $\mathrm{PD}^{2,39}$.

Autosomal recessive homozygous or compound heterozygous loss-of-function mutations were identified in four genes (PRKN, PINK1, ATP13A2 and DNAJC6) in Brazilian patients. $P R K N$ was the most commonly identified gene with pathological mutations in EOPD patients.

In the Brazilian population, as was expected, presence of a family history of PD and earlier age of onset were associated with PRKN mutations. Two-thirds of these patients with PD carrying PRKN mutations in Brazil reported having a family history. As expected, there were different types of mutations in PRKN, including copy number, single nucleotide and frameshift variants. The weighted pooled prevalence in Brazilian EOPD patients (9.3\%) was similar to the estimated global prevalence of PRKN mutations in a previous systematic review on EOPD cases (8.6\%; 95\% CI, 6.0\%-12.4\% $)^{40}$.

SNCA mutations have been found in many countries, comprising $0.2 \%$ of sporadic and $1-2 \%$ of familial PD cases ${ }^{1}$, but no such patients have been described in Brazil, even though six studies explored this. The lack of mutations in VPS35, DJ1 and SYNJ1 among Brazilian patients was not surprising, since these are rare causes of $\mathrm{PD}^{1}$, and only three studies explored these genes. 

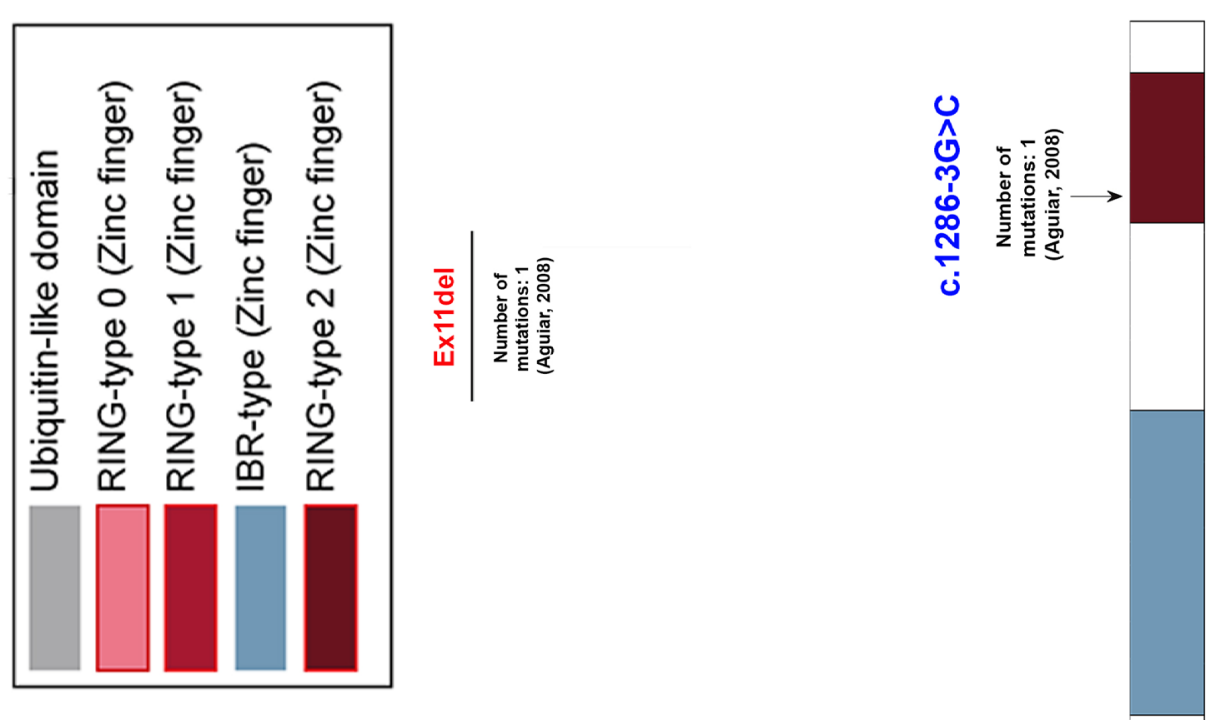

$$
\text { . }
$$

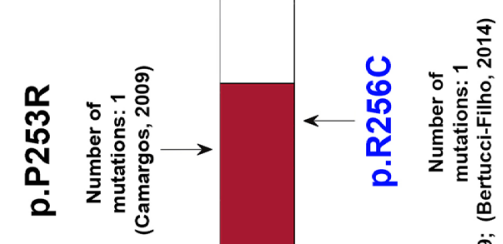

i| in

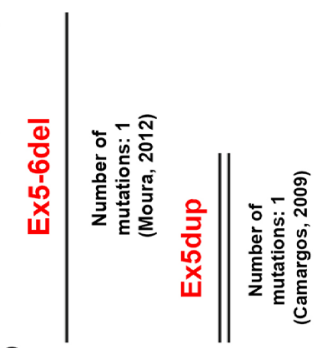

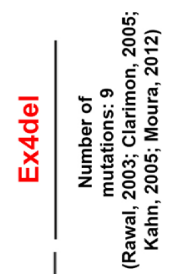

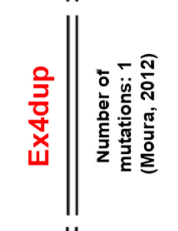
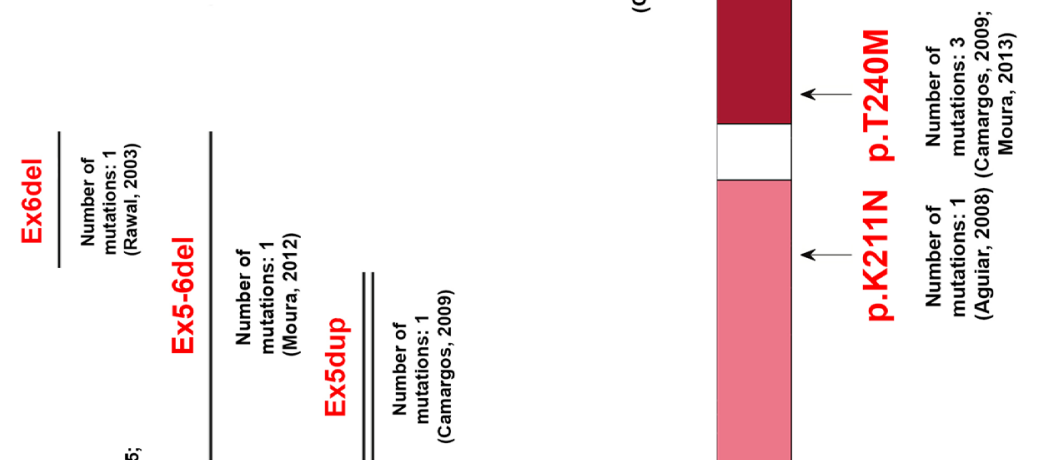

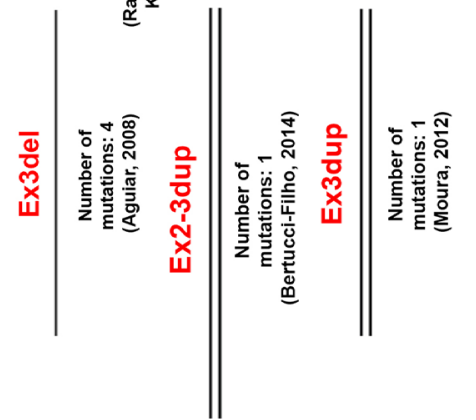

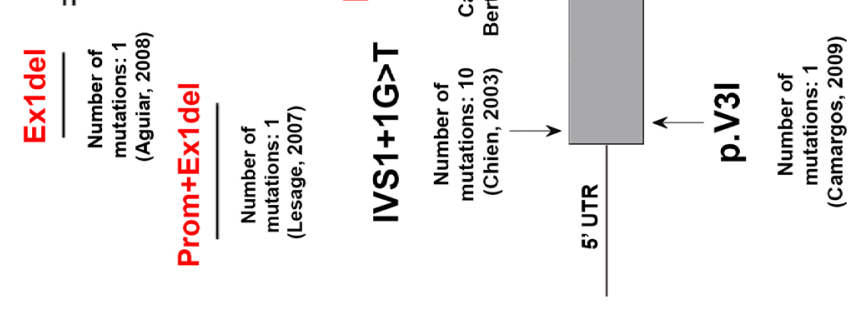

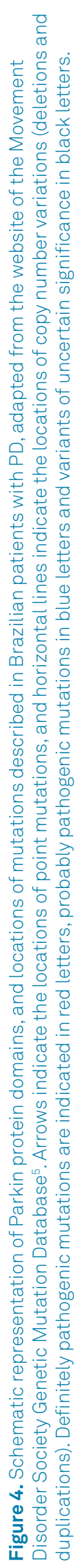


Study

Aguiar et al., 2008

Camargos et al. 2009

Moura et al., 2012

Bertucci-Filho et al., 2014

Overall
Sample size

72
53
102
69

69

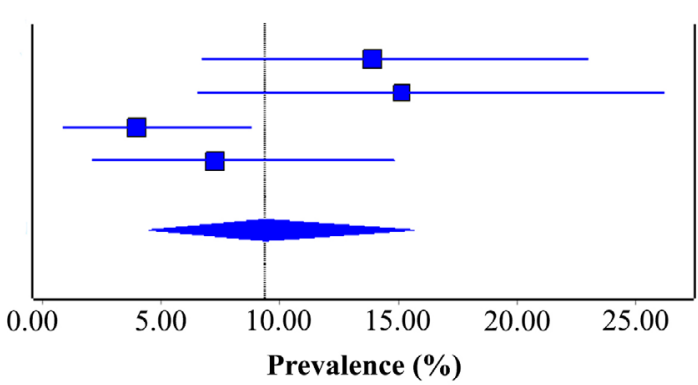

Prevalence $(95 \%$ CI) Weight $(\%)$

$13.8(6.7-22.9) \quad 25.06$

$15.0(6.5-26.1) \quad 22.13$

$3.9(0.8-8.7) \quad 28.12$

$7.2(2.1-14.7) \quad 24.66$

$9.3(4.4-15.6) \quad 100.00$

Figure 5. Forest plot of prevalence of PRKN mutation-positive early-onset Brazilian patients with PD and 95\% confidence intervals for each study included in the meta-analysis. Right-hand column shows per-study prevalence of mutation-positive cases for PRKN (\%), 95\% confidence intervals and the weighting (\%) of each study. The overall weighted prevalence in the random-effects model is denoted by a blue diamond and dotted line. Blue squares are in proportion to the weighting of each study, and blue bars show confidence intervals.

Despite the significant number of studies, it was not possible to accurately estimate the epidemiology of monogenic forms of PD in Brazil. We noted that selection bias was present and that only small numbers of patients were included in most studies. Most of the genetic analyses were among individuals in the southern regions of the country, with a strong contribution from European ancestry, which may have given rise to bias of representation within the Brazilian population (the Northern region has the highest proportion of Amerindian ancestry, and the Northeastern region has the highest proportion of African ancestry) (Figure 1B)4. Therefore, our first conclusion from this systematic review is that there is a lack of robust Brazilian epidemiological studies on the genetics of PD.

We noticed that the level of interactions between Brazilian research groups in different regions of Brazil was low among these genetic studies. It was more common for individual Brazilian groups to participate in collaborative international studies.

Genetic diversity is a major challenge in the field of PD genetics. Like other scientific fields, the majority of the research has been done on individuals with mainly European ancestry. One potential bias in Brazilian studies is that almost all of them were conducted in dedicated tertiary-level referral centers and thus included patients with relatively high a priori likelihood of monogenic disorders.

Another limitation of our analysis was that data from the same patient could have been described in different publications, and this might have caused an overlap between studies. Unfortunately, we were unable to contact the researchers involved in all the original studies in order to gain access to raw data.

In summary, this systematic review showed that there is a lack of robust Brazilian epidemiological studies on the genetics of PD. To date, only five genes associated with monogenic PD have been identified in Brazilian patients with PD (PRKN, LRRK2, PINK1, ATP13A2 and DNAJC6). Studies with larger samples are needed in order to more precisely estimate the frequency of monogenic PD forms in Brazil, a country of continental size and huge genetic variability. We also identified regions of this country that are underrepresented with regard to genetic studies, and we would therefore urge increased representation of these regions in future studies.

\section{ACKNOWLEDGEMENTS}

We would like to thank Prof. Márcia Mattos Gonçalves Pimentel, PhD (Universidade do Estado do Rio de Janeiro), for contributing with data from original publications.

\section{REFERENCES}

1. Lunati A, Lesage S, Brice A. The genetic landscape of Parkinson's disease. Rev Neurol (Paris). 2018 Nov;174(9):628-43. https://doi. org/10.1016/j.neurol.2018.08.004

2. Healy DG, Falchi M, O'Sullivan SS, Bonifati V, Durr A, Bressman S, et al. Phenotype, Genotype, and Worldwide Genetic Penetrance of LRRK2-associated Parkinson's Disease: A Case-Control Study. Lancet Neurol. 2008 Jul;7(7):583-90. https://doi.org/10.1016/s14744422(08)70117-0

3. Brazilian Institute of Geography and Statistics [Internet]. Projections of population in Brazil and Federal Units per sex and age: 2010-2060. Rio de Janeiro: IBGE; [cited 2020 Jul 29]. Accessed July 29, 2020.
4. Moura RR, Coelho AVC, Balbino VQ, Crovella S, Brandão LAC. Metaanalysis of Brazilian Genetic Admixture and Comparison with Other Latin America Countries. Am J Hum Biol. 2015 Sept-Oct;27(5):674-80.

5. Klein C, Hattori N, Marras C. Closing data gaps in genotypephenotype correlations of monogenic Parkinson's disease.J Parkinsons Dis. 2018;8(Suppl 1):S25-30. https://doi.org/10.3233/ jpd-181505

6. Landrum MJ, Lee JM, Benson M, Brown GR, Chao C, Chitipiralla $S$, et al. ClinVar: improving access to variant interpretations and supporting evidence. Nucleic Acids Res. 2018 Jan;46(D1):D1062-7. https://doi.org/10.1093/nar/gkx1153 
7. Teive HA, Raskin S, Iwamoto FM, Germiniani FM, Baran MH, Werneck LC, et al. The G209A Mutation in the Alpha-Synuclein Gene in Brazilian Families With Parkinson's Disease. Arq Neuropsiquiatr. 2001 Sept;59(3-B):722-4. https://doi.org/10.1590/s0004$282 \times 2001000500013$

8. Rawal N, Periquet M, Lohmann E, Lücking CB, Teive HA, Ambrosio G, et al. New Parkin Mutations and Atypical Phenotypes in Families with Autosomal Recessive Parkinsonism. Neurology. 2003 Apr;60(8):137881. https://doi.org/10.1212/01.wnl.0000056167.89221.be

9. Bertoli-Avella AM, Giroud-Benitez JL, Akyol A, Barbosa E, Schaap $\mathrm{O}$, van der Linde $\mathrm{HC}$, et al. Novel Parkin Mutations Detected in Patients With Early-Onset Parkinson's Disease. Mov Disord. 2005 Apr;20(4):424-31. https://doi.org/10.1002/mds.20343

10. Clarimon J, Johnson J, Dogu O, Horta W, Khan N, Lees AJ, et al. Defining the Ends of Parkin Exon 4 Deletions in Two Different Families With Parkinson's Disease. Am J Med Genet B Neuropsychiatr Genet. 2005 Feb;133B(1):120-3.

11. Di Fonzo A, Rohé CF, Ferreira J, Chien HF, Vacca L, Stocchi F, et al. A Frequent LRRK2 Gene Mutation Associated with Autosomal Dominant Parkinson's Disease. Lancet. 2005 JanFeb;365(9457):412-5. https://doi.org/10.1016/s0140-6736(05)17829-5

12. Bonifati V, Rohé CF, Breedveld GJ, Fabrizio E, De Mari M, Tassorelli C, et al. Early-onset Parkinsonism Associated With PINK1 Mutations: Frequency, Genotypes, and Phenotypes. Neurology. 2005 Jul;65(1):8795. https://doi.org/10.1212/01.wnl.0000167546.39375.82

13. Khan NL, Horta W, Eunson L, Graham E, Johnson JO, Chang S, et al. Parkin Disease in a Brazilian Kindred: Manifesting Heterozygotes and Clinical Follow-Up Over 10 Years. Mov Disord. 2005 Apr;20(4):479-84. https://doi.org/10.1002/mds.20335

14. Chien HF, Rohé CF, Costa MDL, Breedveld GJ, Oostra BA, Barbosa ER, et al. Early-onset Parkinson's Disease Caused by a Novel Parkin Mutation in a Genetic Isolate From North-Eastern Brazil. Neurogenetics. 2006 Mar;7(1):13-9. https://doi.org/10.1007/s10048005-0017-x

15. Di Fonzo A, Tassorelli C, De Mari M, Chien HF, Ferreira J, Rohé CF, et al. Comprehensive Analysis of the LRRK2 Gene in Sixty Families With Parkinson's Disease. Eur J Hum Genet. 2006 Mar;14(3):322-31. https://doi.org/10.1038/sj.ejhg.5201539

16. Di Fonzo A, Chien HF, Socal M, Giraudo S, Tassorelli C, Iliceto G, et al. ATP13A2 Missense Mutations in Juvenile Parkinsonism and Young Onset Parkinson Disease. Neurology. 2007 May;68(19):1557-62. https://doi.org/10.1212/01.wnl.0000260963.08711.08

17. Lesage S, Magali P, Lohmann E, Lacomblez L, Teive H, Janin S, et al. Deletion of the Parkin and PACRG Gene Promoter in Early-Onset Parkinsonism. Hum Mutat. 2007 Jan;28(1):27-32. https://doi. org/10.1002/humu.20436

18. Aguiar PC, Lessa PS, Godeiro Jr C, Barsottini O, Felício AC, Borges V, et al. Genetic and Environmental Findings in Early-Onset Parkinson's Disease Brazilian Patients. Mov Disord. 2008 Jul;23(9):1228-33. https://doi.org/10.1002/mds.22032

19. Munhoz RP, Wakutani Y, Marras C, Teive HA, Raskin S, Werneck LC, et al. The G2019S LRRK2 Mutation in Brazilian Patients With Parkinson's Disease: Phenotype in Monozygotic Twins. Mov Disord. 2008 Jan;23(2):290-4. https://doi.org/10.1002/mds.21832

20. Pimentel MMG, Moura KCV, Abdalla CB, Pereira JS, Rosso ALZ, Nicaretta DH, et al. A Study of LRRK2 Mutations and Parkinson's Disease in Brazil. Neurosci Lett. 2008 Mar;433(1):17-21. https://doi. org/10.1016/j.neulet.2007.12.033

21. Santos-Rebouças CB, Abdalla CB, Baldi FJR, Martins PA, Corrêa JC, Gonçalves AP, et al. Co-occurrence of Sporadic Parkinsonism and Late-Onset Alzheimer's Disease in a Brazilian Male With the LRRK2 p.G2019S Mutation. Genet Test. 2008 Dec;12(4):471-3. https://doi. org/10.1089/gte.2008.0042

22. Godeiro Jr C, Aguiar PMC, Felício AC, Barsottini OGP, Silva SMA, Borges V, et al. PINK1 Polymorphism IVS1-7 A-->G, Exposure to Environmental Risk Factors and Anticipation of Disease Onset in Brazilian Patients With Early-Onset Parkinson's Disease. Neurosci Lett. 2010 Jan;469(1):155-8. https://doi.org/10.1016/j. neulet.2009.11.064

23. Barsottini OGP, Felício AC, Aguiar PC, Godeiro-Junior C, Shih MC, Hoexter MQ, et al. Clinical and Molecular Neuroimaging Characteristics of Brazilian Patients With Parkinson's Disease and Mutations in PARK2 or PARK8 Genes. Arq Neuropsiquiatr. 2009 Mar;67(1):7-11. https://doi.org/10.1590/s0004-282×2009000100003

24. Camargos ST, Dornas LO, Momeni P, Lees A, Hardy J, Singleton A, et al. Familial Parkinsonism and Early Onset Parkinson's Disease in a Brazilian Movement Disorders Clinic: Phenotypic Characterization and Frequency of SNCA, PRKN, PINK1, and LRRK2 Mutations. Mov Disord. 2009 Apr;24(5):662-6. https://doi.org/10.1002/mds.22365

25. Santos AV, Pestana CP, Diniz KRS, Campos M, Abdalla-Carvalho CB, Rosso ALZ, et al. Mutational Analysis of GIGYF2, ATP13A2 and GBA Genes in Brazilian Patients With Early-Onset Parkinson's Disease. Neurosci Lett. 2010 Nov;485(2):121-4. https://doi.org/10.1016/j. neulet.2010.08.083

26. Abdalla-Carvalho CB, Santos-Rebouças CB, Guimarães BC, Campos M, Pereira JS, Rosso ALZ, et al. Genetic Analysis of LRRK2 Functional Domains in Brazilian Patients With Parkinson's Disease. Eur J Neurol. 2010 Dec;17(12):1479-81.

27. Moura KCV, Campos Junior M, Rosso ALZ, Nicaretta DH, Pereira JS, Silva DJ, et al. Exon Dosage Variations in Brazilian Patients With Parkinson's Disease: Analysis of SNCA, PARKIN, PINK1 and DJ-1 Genes. Dis Markers. 2012;32(3):173-8. https://doi.org/10.3233/dma2011-0873

28. Moura KCV, Campos Junior M, Rosso ALZ, Nicaretta DH, Pereira JS, Silva DJ, et al. Genetic Analysis of PARK2 and PINK1 Genes in Brazilian Patients with Early-Onset Parkinson's Disease. Dis Markers. 2013;35(3):181-5. https://doi.org/10.1155/2013/597158

29. Quadri M, Fang M, Picillo M, Olgiati S, Breedveld GJ, Graafland J, et al. Mutation in the SYNJ1 Gene Associated with Autosomal Recessive, Early-Onset Parkinsonism. Hum Mutat. 2013 Sept;34(9):1208-15. https://doi.org/10.1002/humu.22373

30. Chien HF, Figueiredo TR, Hollaender MA, Tofoli F, Takada LT, Pereira LV, et al. Frequency of the LRRK2 G2019S Mutation in Late-Onset Sporadic Patients With Parkinson's Disease. Arq Neuropsiquiatr. 2014 May;72(5):356-9. https://doi.org/10.1590/0004-282×20140019

31. Bertucci Filho D, Munhoz RP, Lesage S, Brice A, Raskin S, Teive HAG. Prevalence and Phenotype of patients with PARK2 or PARK8 Gene Mutations in an Early-Onset Parkinsonism Brazilian Cohort. J J Neur Neurosci. 2014;1(2):003.

32. Longo GS, Pinhel MAS, Gregório ML, Oliveira BAP, Quinhoneiro DCG, Tognola WA,et al. Alpha-synuclein A53T Mutation Is Not Frequent on a Sample of Brazilian Parkinson's Disease Patients. Arq Neuropsiquiatr. 2015 Jun;73(6):506-9. https://doi.org/10.1590/0004$282 \times 20150032$

33. Pimentel MMG, Rodrigues FC, Leite MAA, Campos Júnior M, Rosso AL, Nicaretta DH, et al. Parkinson Disease: $\alpha$-synuclein Mutational Screening and New Clinical Insight Into the p.E46K Mutation. Parkinsonism Relat Disord. 2015 Jun;21(6):586-9. https://doi. org/10.1016/j.parkreldis.2015.03.011

34. Spitz M, Pereira JS, Nicareta DH, Abreu GM, Bastos EF, Seixas TL, et al. Association of LRRK2 and GBA Mutations in a Brazilian Family With Parkinson's Disease. Parkinsonism Relat Disord. 2015 Jul;21(7):825-6. https://doi.org/10.1016/j.parkreldis.2015.03.029

35. Olgiati S, Quadri M, Fang M, Rood JPMA, Saute JA, Chien HF, et al. DNAJC6 Mutations Associated with Early-Onset Parkinson's Disease. Ann Neurol. 2016 Feb;79(2):244-56. https://doi.org/10.1002/ ana.24553

36. Abreu GM, Valença DCT, Campos Júnior M, Silva CP, Pereira JS, Leite MAA, et al. Autosomal Dominant Parkinson's Disease: Incidence of Mutations in LRRK2, SNCA, VPS35 and GBA Genes in Brazil. Neurosci Lett. 2016 Dec;635:67-70. https://doi.org/10.1016/j. neulet.2016.10.040 
37. Cornejo-Olivas M, Torres L, Velit-Salazar MR, Inca-Martinez M, Mazzetti P, Cosentino C, et al. Variable Frequency of LRRK2 Variants in the Latin American Research Consortium on the Genetics of Parkinson's Disease (LARGE-PD), a Case of Ancestry. NPJ Parkinsons Dis. 2017 Jun;3:19. https://doi.org/10.1038/s41531-017-0020-6

38. Silva CP, Abreu GM, Acero PHC, Campos Júnior M, Pereira JS, Ramos SRA, et al. Clinical Profiles Associated With LRRK2 and GBA Mutations in Brazilians With Parkinson's Disease. J Neurol Sci. 2017 Oct;381:160-4. https://doi.org/10.1016/j.jns.2017.08.3249
39. Guedes LC, Ferreira JJ, Rosa MM, Coelho M, Bonifati V, Sampaio C. Worldwide frequency of G2019S LRRK2 mutation in Parkinson's disease: a systematic review. Parkinsonism Relat Disord. 2010 May;16(4):237-42. https://doi.org/10.1016/j.parkreldis.2009.11.004

40. Kilarski LL, Pearson JP, Newsway V, Majounie E, Knipe MDW, Misbahuddin A, et al. Systematic review and UK-based study of PARK2 (parkin), PINK1, PARK7 (DJ-1) and LRRK2 in early-onset Parkinson's disease. Mov Disord. 2012 Oct;27(12):1522-9. https://doi. org/10.1002/mds.25132 